\title{
Assessing Microanalytical Performance Using Secondary Standards: Results of an Electron Probe Interlaboratory Comparison Using Four Natural Volcanic Glasses
}

\author{
S.C. Kuehn, ${ }^{*}$ G.G. Froese, ${ }^{* *}$, and P.A.R. Shane ${ }^{* * *}$
}

* Department of Physical Science, Concord University, PO Box 1000, CB \#F20, Athens, WV 24712-1000

** Department of Earth and Atmospheric Sciences, University of Alberta, 1-26 Earth Sciences Building, Edmonton, AB T6G 2E3, Canada

*** School of Environment, University of Auckland, Private Bag 92019, Auckland, New Zealand

Routine analysis of well-characterized secondary standards is essential for evaluating the results from any analytical method. Recently, the international tephrochronology community conducted a large intercomparison of electron-beam microanalytical data using four well-characterized natural glasses as secondary standards [1]. Data was submitted from 27 instruments at 24 institutions in 9 nations. The intercomparison was motivated by (1) the desire to assess the quality of data currently being produced and (2) to stimulate improvements in analytical protocols, improvements in data reporting practices, and increased use of secondary standards.

Tephrochronology is an important technique for correlation and dating in the Earth sciences. It is based primarily upon the chemical fingerprinting of the glass fraction of widely-dispersed volcanic ashes. Most commonly, chemical fingerprinting is performed using electron probe microanalysis (EPMA) and scanning electron microscopy with energy-dispersive X-ray spectroscopy (SEM-EDS) $[2,3]$. As compositional differences between glasses from individual volcanic eruptions can sometimes be subtle, high levels of precision, accuracy, and reproducibility (both within and between laboratories) are required for reliable identification. One key analytical challenge that must be overcome to obtain data of sufficient quality is "sodium-loss" which affects Na-bearing silicate glasses and some minerals. Na-loss appears as an approximately exponential and irreversible decline in $\mathrm{Na} \mathrm{X}$-ray count rates with time during exposure to the electron beam $[4,5,6]$. As the $\mathrm{Na}$ count rate declines, $\mathrm{Si}$ and $\mathrm{Al} \mathrm{X}$-ray count rates increase to a lesser degree. The rate of change is strongly affected by both analytical conditions and sample composition.

To assess data quality, participating laboratories were each supplied with an unpolished mount containing four glasses that were selected to cover a range of compositions and to exhibit different rates of sodium-loss (Fig. 1). The samples are: (1) rhyolitic Lipari obsidian ID3506 [7], (2) phonolitic Sheep Track tephra, (3) basaltic Laki 1783 A.D. tephra, and (4) secondarily hydrated, rhyolitic Old Crow tephra. Most laboratories submitted extensive procedural details in addition to their analytical results. Most used some combination of defocused or rastered beam and modest beam current to reduce Na-migration. Despite substantial variety in procedures and calibration standards, mean values generally compare favorably between labs and with other reference data. The major exception is $\mathrm{Na}_{2} \mathrm{O}$ values for the phonolitic glass. Only one-half of the submitted data sets had mean values within 1 standard deviation of the $8.2 \mathrm{wt} \% \mathrm{Na}_{2} \mathrm{O}$ value obtained from XRF and ICPAES analyses of high-purity glass separates.

Based on the abundant microanalytical data, XRF and ICP-AES on bulk obsidian or glass separates, and other published data (see [1] for details), we have developed a set of recommended working 
values for the four reference glasses (Table 1). These are based primarily on the median values computed after the removal of outliers. The recommended values also take into consideration the tendency for EPMA results to be biased toward lower $\mathrm{Na}_{2} \mathrm{O}$ and higher $\mathrm{SiO}_{2}$ and $\mathrm{Al}_{2} \mathrm{O}_{3}$ values because of sodium migration during analysis.

Samples of Lipari obsidian ID3506 may be obtained from the Harvard Mineralogical Museum. Small quantities of the Mt. Edziza Sheep Track tephra may be obtained from S. Kuehn. Samples of Old Crow tephra may be obtained from D. Froese.

\section{References}

[1] S.C. Kuehn et al, Quaternary International, submitted.

[2] A.M. Sarna-Wojcicki and J.O. Davis in Morrison, R.B. (ed.), The Geology of North America, Vol. K-2, Geological Society of America, Boulder, (1992) 93.

[3] D.J. Lowe, Quaternary Geochronology, DOI: 10.1016/j.quageo.2010.08.003

[4] C.H. Nielsen and H. Sigurdsson, American Mineralogist, 66 (1981) 547.

[5] J.B. Hunt and P.G. Hill, Journal of Quaternary Science, 16, (2001) 105.

[6] G.B. Morgan and D. London, American Mineralogist, 90 (2005) 1131.

[7] S.C. Kuehn et al., Eos Transactions of the AGU, Fall Meeting Suppl., (2009) abs. V31E-2010.
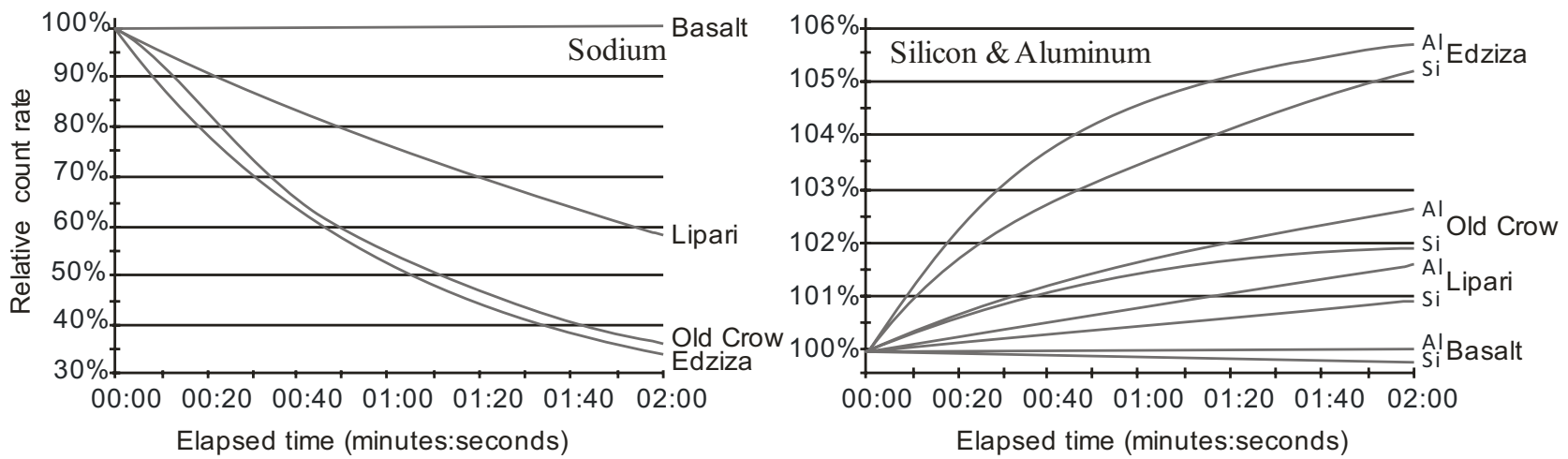

FIG. 1. Relative X-ray count rates with time. Acquired in $2 \mathrm{~s}$ intervals using a 10nA current and $10 \mu \mathrm{m}$ defocused beam.

TABLE 1. Recommended working values for the four reference glasses.

\begin{tabular}{|c|c|c|c|c|c|c|c|c|c|c|c|c|c|c|c|c|c|c|}
\hline & $\mathrm{SiO}_{2}$ & $\mathrm{TiO}_{2}$ & $\mathrm{ZrO}_{2}$ & $\mathrm{Al}_{2} \mathrm{O}_{3}$ & $\mathrm{FeO}_{\mathrm{T}}$ & $\mathrm{BaO}$ & $\mathrm{MnO}$ & MgO & $\mathrm{CaO}$ & $\mathrm{Na}_{2} \mathrm{O}$ & $\mathrm{K}_{2} \mathrm{O}$ & $\mathbf{P}_{2} \mathbf{O}_{5}$ & $\mathbf{C l}$ & $\mathbf{F}$ & $\mathrm{SO}_{2}$ & $\begin{array}{l}\text { Other } \\
\text { Trace }\end{array}$ & $\begin{array}{c}\mathrm{OH}, \\
\mathrm{H}_{2} \mathrm{O} \\
\end{array}$ & Sum \\
\hline \multicolumn{19}{|l|}{ Lipari obsidian } \\
\hline$\overline{\text { nded }}$ & 74.10 & 0.074 & 0.023 & 13.10 & .55 & 0.0 & 0.065 & 0.041 & 0.735 & 4.06 & 5.13 & 0.008 & 0.341 & 0.151 & 0.007 & 0.098 & 0.64 & 99.99 \\
\hline Iי & 0.96 & 0.026 & 0.014 & 0.34 & .06 & 0.005 & 0.030 & 0.021 & 0.053 & 0.28 & 0.26 & 0.016 & 0.034 & 0.042 & 0.011 & & 0.02 & \\
\hline \multicolumn{19}{|c|}{ Edziza Sheep Track tephra } \\
\hline Recommended & 61.55 & 0.237 & 0.154 & 17.55 & 4.55 & 0.004 & 0.133 & 0.123 & 1.090 & 8.21 & 5.30 & 0.038 & 0.210 & 0.197 & 0.021 & 0.120 & 0.70 & 100.05 \\
\hline $2 \sigma(95$ & 1.03 & 0.024 & 0.020 & 0.59 & 0.27 & 0.003 & 0.033 & 0.026 & 0.114 & 0.28 & 0.31 & 0.024 & 0.031 & 0.065 & 0.010 & & & \\
\hline \multicolumn{19}{|l|}{ Laki 1783 tephra } \\
\hline Recommended & 49.69 & 3.08 & & 12.97 & 14.14 & $n / a$ & 0.230 & 5.40 & 9.69 & 2.87 & 0.464 & 0. & 0. & 0.108 & 0.093 & & & 99.09 \\
\hline $2 \sigma(95 \% \mathrm{Cl})$ & 0.88 & 0.18 & & 0.56 & 0.58 & & 0.061 & 0.17 & 0.28 & 0.26 & 0.033 & 0.046 & 0.010 & 0.085 & 0.036 & & & \\
\hline \multicolumn{19}{|l|}{ Old Crow tephra } \\
\hline d & 71.90 & & & 12.57 & 1.63 & & & & & & 3.56 & & & & 0.012 & 0.061 & 4.12 & 100.0 \\
\hline $2 \sigma(95 \% \mathrm{Cl})$ & 1.00 & 0.049 & 0.006 & 0.34 & 0.14 & 0.011 & 0.029 & 0.027 & 0.050 & 0.26 & 0.26 & 0.014 & 0.047 & 0.094 & & & & \\
\hline
\end{tabular}

